\title{
Comunicar em tempos de Covid-19: os desafios enfrentados no Brasil
}

\section{Communicating in times of Covid-19: Challenges for Brazil}

$\sim_{2}^{4}$ uinhentas mil mortes em decorrência da covid-19 no Brasil, marco alcançado em 19 de junho de 2021. Só em escrever essa frase já pesa a mão. Além dos números exorbitantes, parece que tudo em relação à crise sanitária atual nos transborda: a tristeza, a indignação e a sensação de impotência. Dizia Hemingway que, ao escrever, deveríamos buscar as palavras mais precisas possíveis. Não sei se elas existem no contexto da atual crise sanitária no país.

Muitos dirão que outros países viveram dias horríveis, como os Estados Unidos e muitos países europeus, e vivem atualmente, como no caso da Índia, e tiveram problemas, dificuldades e gestão da crise questionável, mas ouso dizer que algumas coisas só acontecem no Brasil. Ou só acontecem mais intensamente no Brasil.

A politização da saúde é uma delas. Muitas pessoas estão tomando decisões sobre sua saúde influenciadas por suas opções políticas em um momento que estamos vivendo a maior crise sanitária do século, ou seja, estão tomando decisões com base em suas emoções. Quando falamos em emoção, falamos em paixão, um terreno onde há pouco espaço para a racionalidade. Um terreno em que não há argumento possível que faça algum sentido para essas pessoas.

É nesse solo onde são plantadas e cultivadas as fake news, entendidas como "notícias baseadas em informações falsas embaladas para que pareçam notícias reais para enganar os leitores a fim de obter benefícios econômicos ou ideológicos" (Tandoc Jr., Jenkins, \& Craft, 2019, p.674)¹ . Em 2017, o Dicionário Oxford já havia considerado fake news como a palavra do ano (Elias, 2019).

Muitos já acreditam que as noticias falsas, na atual crise sanitária, são uma epidemia dentro da epidemia, que alimenta uma onda de desinformação e medo na população (Ramón Fernández, 2020). Alguns exemplos atuais: as que disseminam dúvidas sobre a efetividade das máscaras, do distanciamento social e agora, durante a vacinação contra a covid-19, informações que questionam

\footnotetext{
1 Tradução nossa: "articles based on false information packaged to look like real news to deceive readers either for financial or ideological gain."
}

seus benefícios ou tentam atemorizar as pessoas. Circula nas redes sociais um vídeo em que diz que, por meio da vacina, estão injetando nas pessoas metais pesados ou matérias com propriedades magnéticas. Para confirmar essa hipótese, a pessoa deve colocar um imã ou metal no braço vacinado que ficará pegado pela atração dos metais pesados que supostamente há na vacina.

Segundo um estudo realizado por Barcelos et al. (2021), que analisou as fake news que circularam no Brasil nos seis primeiros meses da pandemia, as redes sociais que mais vincularam esses conteúdos foram 0 WhatsApp e o Facebook. Os autores ainda constataram que os conteúdos tinham um perfil de posicionamento político e de desinformação sobre o número de casos e de mortes em decorrência da covid, bem como sobre as medidas preventivas no combate ao coronavirus e ao seu tratamento.

Esse tipo de conteúdo sustenta a desconfiança nas instituições científicas, que já produziram conhecimento que salvou milhões de vidas na história recente da humanidade. A vacinação é uma das formas com melhor custo-benefício para prevenir doenças, evitando, por exemplo, cerca de 2 a 3 milhões de mortes todos os anos (OMS, 2019). Nesta atual crise sanitária, a imunização representa a esperança de que se possa vencer o coronavirus, e o mundo enfim recupere a sua normalidade (Wiysonge et al., 2021). Muitos países já estão sentindo os benefícios da vacinação nos casos em que já há uma alta cobertura vacinal.

É nesse contexto tão complexo que precisamos repensar o papel da comunicação e resgatar o que significa comunicar. A palavra comunicação vem do latim comunicatio: co que significa simultaneidade, encontro; munis, estar encarregado de; e tio, que se relaciona com atividade, e nos leva a compreender a comunicação 
como uma atividade realizada com o outro, uma atividade coletiva (Rangel-S, 2008).

Porque comunicar é mais do que transmitir informações. É fundamental buscar reciprocidade no ato de comunicar. Há encontros e talvez desentendimentos na hora de nos comunicarmos, o que contribui ou afeta nosso relacionamento com a família, amigos ou no trabalho. Isso sugere que devemos dedicar mais atenção, além do nosso tempo, durante o processo de comunicação, pois ela desempenha um papel fundamental na esfera social. O pedagogo Paulo Freire ainda nos lembra que não existem sujeitos passivos no ato de comunicar (Freire, 983). Temos que ser responsáveis quando nos comunicamos, e o que comunicamos.

Com a possibilidade que as redes sociais nos dão, de se fazer ver e ouvir, a comunicação deveria ser um ato consciente. Isso ganha ainda mais força quando pensamos em uma pandemia global em que cada ação, por menor que possa parecer, como compartilhar um conteúdo qualquer no Whastapp ou Facebook, pode ter implicações muito sérias em relação à saúde das pessoas. Ou seja, as fake news parecem ser um vírus tão daninho quanto o próprio SARS-Cov-2.

Muitos dirão que é impossível controlar os produtores das fake news, mas é possível, sim, evitar o seu compartilhamento. $O$ que vemos é a disseminação de informações sem credibilidade e sem critérios, sem 0 senso comum de coletividade que devemos ter, seja pelo cargo ou profissão que exercemos, que carrega em si esta responsabilidade, que vai desde o governo, políticos até professores, profissionais de saúde, entre outros, ou seja pelo fato que todos somos e devemos atuar como cidadãos.

O governo, as instituições de saúde pública e as instituições científicas também devem participar tão ativamente quanto possível naluta contra a desinformação.

No caso do governo brasileiro, qual é, afinal, a sua atuaçãono combateà desinformação relacionada aum tema tão fundamental quanto à pandemia atual? Qual a política de comunicação adotada? O que vivemos atualmente é um paradoxo, com casos dos próprios representantes do governo, como o que ocorreu com o ministro da saúde, em janeiro de 2021, cujo post foi sinalizado pelo Twitter por disseminar informações potencialmente prejudiciais relacionadas a covid (Hallal, 2021).

Em crises sanitárias é fundamental garantir uma comunicação pública eficiente. Saber administrar momentos de crise sanitária por meio de uma comunicação adequada não é tarefa fácil e exige esforço e planejamento. A omissão ou manipulação de informações pode gerar descrença nas instituições públicas ou científicas, daí a importância de garantir a transparência no conteúdo e nos dados divulgados. Quando falamos aqui em comunicação pública não estamos falando do uso de ações com o objetivo de fazer publicidade governamental.

Todos esses elementos reforçam a importância do papel da comunicação e saúde, em que o governo e as instituições científicas devem investir recursos e tempo no aprimoramento dessa área, para que a sociedade tenha informações confiáveis sobre questões que possam ter implicações diretas em sua saúde.

Desinformação se combate com informação de qualidade e transparência, assim como com normas que regulamentem as medidas que devem ser tomadas no combate às notícias falsas (Ramón Fernández, 2020). Deve ser um esforço conjunto do governo e de toda a sociedade.

A abertura de canais de comunicação eficientes com os cidadãos também é essencial para garantir que suas demandas e necessidades sejam ouvidas; que se sintam contemplados em suas angústias e dúvidas em um momento tão crucial em que vivemos. Por outro lado, para dar conta deste contexto e garantir melhor acesso a conteúdos de qualidade, os órgãos públicos devem investir na comunicação pública para que as pessoas possam tomar decisões sobre sua saúde com embasamento científico consistente.

\section{Referências bibliográficas}

Barcelos, T.N., Muniz, L.N., Dantas, D.M., Cotrim Junior, D.F., Cavalcante, J.R., \& Faerstein, E. (2021). Análise de fake news veiculadas durante a pandemia de COVID-19 no Brasil. Revista Panamericana de Salud Pública, 45, e65. Doi: https://doi.org/10.26633/ RPSP.2021.65 
Elias, C. (2019). Science on the Ropes. Decline of Scientific Culture in the Era of Fake news. Switzerland: Springer-Nature.

Hallal, P. C. (2021). SOS Brazil: science under attack. Lancet, 397, 373-374.

Paulo, F. (1983). Extensão ou comunicação? Rio de Janeiro: Paz e Terra.

Ramón Fernández, F. (2020). Comunicación y noticias falsas en relación al COVID-19: algunas reflexiones sobre la información, la desinformación y propuestas de mejora. Revista Española de Comunicación en Salud, S1, S253-S264.

Rangel-S, M. L. (2008). Dengue: educação, comunicação e mobilização na perspectiva do controle-propostas inovadoras. Interface (Botucatu), 12(25), 433-41.

Tandoc Jr, E.C., Jenkins, J., \& Craft, S. (2019). Fake news as a Critical Incident in Journalism. Journalism Practice, 13(6), 673-689.

Organização Mundial da Saúde. (2019). Ten threats to global health in 2019. 2019. Recuperado de: https://www.who.int/news-room/spotlight/ten-threatsto-global-health-in-2019.

Wiysonge, C. S., Ndwandwe, D., Ryan, J., Jaca, A., Batouré, O., Melanga Anya ,B.P., \& Cooper, S. (2021). Vaccine hesitancy in the era of COVID-19: could lessons from the past help in divining the future? Human Vaccines \& Immunotherapeutics, 8, 1-3. Doi: 10.1080/21645515.2021.1893062

\section{Andrea Langbecker}

Editora asociada RECS

అalangbecker@hotmail.com 